\title{
San La Muerte (Argentina). Devoción y existencia. ENTRE LOS DIOSES Y EL ABANDONO
}

\author{
Walter Alberto Calzato
}

Resumen: En este artículo analizo la praxis devocional del culto a San La Muerte en la provincia de Buenos Aires (Argentina). Interpreto cómo los devotos entablan su relación con el santo y cómo la traducen en sus consideraciones sobre el más allá. Ellos encuentran, en la vida cotidiana y en el sentido común los parámetros para entender su devoción, lo que les permite encontrar su propio sentido. La experiencia religiosa, definida por autores e informantes, nos da un punto de referencia para entender cómo es, en el fondo, esta devoción.

Palabras clave: San La Muerte, existencia, orfandad, vida cotidiana, sentido común, escatología, desescatologización, experiencia religiosa, finitud.

Enviado a dictamen: 19 de febrero de 2008.

Aprobación: 31 de mayo de 2008.

Walter Alberto Calzato, licenciado en Ciencias Antropológicas por la Universidad de Buenos Aires, Casa de Formación Santa Verónica, hermanas Clarisas Capuchinas, Cuautitlán Izcalli, Estado de México. Temas de investigación: religiosidad popular, teología; correo electrónico: wcalzato@yahoo.com.ar.
Abstract: This paper is about the devotional praxis of the San La Muerte popular cult in Argentina. There are two ideas used as basis to analyze this popular cult: one is the concept of orphanhood, and the other one is finitude. They both are related to the saint and its considerations about the concept of After Life. The context where the devotional praxis on San LaMuerte is analyzed refers to everyday life and to the context of the people's common sense linked to the meaning of religious experience.

Key words: San La Muerte, life, orphanhood, everyday's life, normal behavior, scatology, religious experience and finitude.

\section{Introducción}

$\longrightarrow$ presente trabajo posee dos objetivos básicos: el primero es tratar de definir una concepción del fenómeno religioso partiendo de un modelo acerca de la situación existencial del hombre y de la cultura. Encontrar el hilo de Ariadna en la experiencia devocional es, sabemos, sumamente difícil; cada definición es un nuevo intento donde se juegan, en un mismo cedazo, la praxis general del culto, las vivencias de cada uno de los devotos y la experiencia de vida del propio antropólogo.

Lejos se encuentra la búsqueda de una definición a ultranza. Nada lo es en el terreno religioso. De lo menos que podemos hablar en cuanto a experiencia religiosa es 
de univocidad. Se pretende una orientación, un nuevo juego, una nueva manera de aprehender algo que continuamente se nos escapa y que, a través de nuestras metodologías y enfoques, tratamos de llevar al terreno de la comprensión.

Como segundo objetivo quiero llevar estas nociones acerca de la experiencia religiosa al terreno de la religiosidad popular, dilucidar cuál es su horizonte, dónde se deposita ese saber, cuál es su transformación y los parámetros que los devotos manejan de manera concreta para resolver sus cuestiones en la vida de todos los días, es decir, cómo se concretiza eso que solemos llamar lo sagrado. Aquí, el lente de nuestra visión disminuye sensiblemente y se concentra, como modelo o estudio de caso, en la devoción popular a San La Muerte.

\section{Orfandad}

Para definir el significado de la experiencia religiosa parto del siguiente marco, que se ampliará a lo largo del presente artículo: la absoluta finitud existencial del hombre y la búsqueda que lo lleva a preguntarse, dentro del ámbito de lo sagrado, sobre el sentido de la vida, del mundo, su devenir y el significado de la muerte (Chapp, 1991). Este planteamiento conlleva tres puntos esenciales:

a) La definición, por parte de Martín Heidegger, acerca de la existencia.

b) El aporte de Rodolfo Kusch a los planteamientos de Heidegger

c) Las definiciones sobre la experiencia religiosa que brinda la teología, tanto católica como protestante.

\section{Existencia}

La posición de Heidegger puede ser definida de la siguiente manera. El Da-sein o ser ahí nos habla de la condición del hombre en el mundo; condición que no fue definida correctamente por la metafísica occidental. Esto se denomina "olvido del ser", es decir, que la pregunta por el ser no ha sido una cuestión primordial en los sistemas filosóficos de occidente. Esta ontología fundamental ha sido reemplazada por ontologías particulares, como las ciencias experimentales y positivas. Pero, según Heidegger, la cuestión del ser no es un problema de verticalidad, es un error buscar la trascendencia fuera del hombre o fuera de este mundo. Por eso, el "ser ahí" es el mundo de la vida, el mundo cotidiano material, el suelo que pisan nuestros pies, donde resolvemos - $\mathrm{o}$ tratamos de hacerlo- todos nuestros pesares, que pueden ser definidos como el mundo de lo cotidiano. De todas maneras, el vivir en la in-autenticidad del ser, en este olvido de la pregunta fundamental, hace que surjan de manera irremediable el miedo y la angustia. Según Heidegger el hombre es el único ente privilegiado que puede "pensar el ser". De esta manera deber indagar y pensar sobre su propio ser y su existir; de lo contrario se cae en la in-autenticidad del ser, el olvido de sí mismo, el evadirse a cuestiones que no se refieren a la pregunta sobre nosotros mismos. Occidente, a través de Platón, Aristóteles, Descartes o Nietzsche, planteó un modelo distinto (ontologías particulares) que se alejó de la pregunta acerca de nuestra propia existencia, que es la ontología fundamental. Por otro lado, como "seres para la muerte", la existencia nos determina y configura el accionar de nuestras vidas. Por eso, y asociado profundamente con el Da-sein, el hombre ha sido arrojado a este mundo, que permanece antes y después de nosotros, sin habernos responsabilizado previamente. Esto genera el miedo profundo al devenir. Aunque Heidegger no dejó inconcluso este punto de vista, dado que ofreció una salida a esta situación, nos centramos en la definición de angustia, que el filósofo supo trazar con una profundidad meritoria, donde se atisba a San Agustín, San Pablo y Pascal, como parámetros de pensamiento (Steiner, 1999). Esta búsqueda del sentido de la vida, de nuestro existir y de nuestra condición nos lleva, inexorablemente, al terreno religioso, donde se acomodan y persisten las preguntas más profundas acerca de nuestra condición y existencia. 


\section{Estar ahí, nomás}

Uno de los pocos antropólogos argentinos que transitó los planteamientos hermenéuticos de Martín Heidegger fue Rodolfo Kusch (1922-1979). Este antropólogo-filósofo define la cultura del siguiente modo:

El concepto de cultura está tomado aquí en otro sentido que el corriente (...) Cultura no es sólo el acervo espiritual que el grupo brinda a cada uno y que es aportado por la tradición, sino además es el baluarte simbólico en el cual uno se refugia para defender la significación de su existencia. Cultura implica una defensa existencial frente a lo nuevo, porque si careciera uno de ella no tendría elementos para hacer frente a una novedad incomprensible (Kusch, 1991:14).

Esta definición nos permite aventurarnos en otro concepto de este antropólogo: suelo. Se trata de instalar la existencia. Para eso se necesita un punto de apoyo gravitatorio para poder situar una forma de vida. Este suelo, o molde, se traduce primero como un fundamento o punto de apoyo espiritual, como arraigo de toda cultura, dado que se recurre a ella en los momentos más críticos del vivir, cuando necesitamos saber que pertenecemos a un suelo que nos identifica y da sentido a nuestro existir. Un comentarista lo define:

Como hemos visto, el horizonte simbólico y el suelo son las dos dimensiones que estructuran un espacio cuyo eje es el sujeto cultural. El suelo-molde simbólico que hace posible la instalación de una vida (...) es el desde donde irreductible de una comunidad. Sin suelo no hay arraigo, a la vez que sin arraigo no hay reclamo por lopropio. Es así que cuando se pierdeel suelo, también se pierde elfundamento que da gravidez al existir (Gazques, 1989: 37).

Aunque por razones de espacio es imposible abarcar algunos tópicos de Kusch de sumo interés para el presente trabajo, las nociones de cultura y de suelo nos permiten, primero, situarnos en la perspectiva existencial, luego "instalar" las definiciones de "experiencia religiosa" y por último aventurar una interpretación del culto a San La Muerte bajo estas perspectivas.

Este autor estuvo durante muchos años en territorio boliviano y peruano, trabajando en religiosidad popular. Planteó la necesidad de considerar el pensamiento americano como propio, a diferencia del europeo occidental. Sus consideraciones son de suma importancia para entender el pensamiento popular desde el punto de vista del "puro existir". La noción de "ser" involucra a las historias oficiales e institucionales. Ser que se desarrolla en la historia positiva. El "estar", en cambio, transcurre en otro plano de la existencia y es propio de América. El "estar" de la cultura americana, según Kusch, es el trascurrir en el puro vivir, el asumirse como ser finito, el aceptar la infinitud, el no desesperar, el saber que los dioses pueden estar con nosotros o no. Es entender que lo trágico es una condición de la existencia que puede aparecer en cualquier instante. Por eso las etnias americanas concentran su atención en los dioses y en la seguridad que los mismos pueden suministrar. En esta oscilación se entiende la actitud del pensamiento americano frente al agresivo pensamiento burgués occidental que opera sobre la noción de transformación, centrándose en el futuro, evadiendo las preguntas fundamentales acerca de la existencia y asentando ésta sobre elementos (objetos, cosas, ideas) que se encuentran fuera del propio existir (Kusch, 1975, 1976, 1986).

\section{Experiencia religiosa}

Paul Tillich (1972) denomina a la experiencia religiosa como la "preocupación última". Lo religioso no permite otra preocupación, todas las demás quedan relegadas. No hay lugar para otra situación, abarca la totalidad de la existencia. Esto significa que no podemos escondernos de ella, no podemos dejarla para después, o incluirla en una parte dividida de nuestra alma. En otros escritos 
este autor la denomina como "el coraje de existir", que hace de la preocupación religiosa una cuestión infinita, incondicional, total, que indica el carácter existencial de lo religioso. Frente a la pregunta por el contenido de esta preocupación última, este autor responde que es aquello que determina nuestro ser o no ser en el sentido de realidad humana. Cuando el hombre se preocupa por el significado de su existencia se enfrenta con su ser para la muerte tal como hemos visto en Heidegger. De aquí que la preocupación religiosa hace que las demás categorías particulares y accidentales se encuentren minimizados por el destino último.

Para Walter Kasper (1986) es necesario, en primer lugar, partir de una idea general de experiencia para mostrar cómo ésta se abre a la vida cotidiana de los hombres. El primer problema es el carácter multifacético del término. No es unívoco. Incluso las ciencias naturales utilizan el término, supuestamente de manera objetiva, aunque las mismas ciencias han demostrado que el positivismo antimetafísico es una metafísica de lo positivo. Nos queda la subjetividad. Pero es tan peligrosa como la primera idea. Se corre el peligro de hacer una proyección del propio mundo, reduciendo la experiencia a cuestiones personales. Hasta los místicos desconfiaron de ella:

La experiencia abarca ambas cosas: el encuentro objetivo y la impresión subjetiva. Es el resultado del juego de la realidad objetiva y el trato subjetivo con el entorno. La experiencia es el choque con la realidad y la interpretación de ese choque en palabras, imágenes, símbolos y conceptos (Kasper, 1986: 106).

Pero esta experiencia es el producto de una historicidad que no se presenta en las percepciones del presente. Es el producto de nuestro pasado. Por eso, Aristóteles la relacionaba con la memoria. Es a través del lenguaje donde aprendemos, percibimos y entendemos nuestro presente. Es el recuerdo de la experiencia pasada lo que nos ayuda a entender y configurar nuestra experiencia del presente. Esta dialéctica entre pasado, presente y futuro indica que no vivimos de experiencias inmediatas y cerradas; éstas son fecundas cuando la misma realidad de nuestro quehacer nos enfrenta a situaciones de cambio inesperado, cuando se rompen nuestros planes. Cuando la experiencia de la propia finitud nos abarca totalmente aparece de lleno la experiencia religiosa. Pero ésta puede definirse como la experiencia con nuestra experiencia; es, en último término, el trato con la finitud. Experiencia que no es inmediata, sino mediata, dado que la hacemos con las restantes experiencias de vida, lo que llevamos de nuestra historia, de nuestro pasado. De esta manera, y por su carácter, se convierte en la experiencia fundamental, única. Tal es el caso de la conversión paulina (disclosure situation) o situación de descubrimiento y cambio. ${ }^{1}$

\section{San La Muerte: consideraciones generales}

El culto a San La Muerte se desarrolla en las provincias de Corrientes, Formosa, Chaco, Santa Fe, Gran Buenos Aires (Morón, Claypole, Wilde, Villa Dominico, Laferrere, José C. Paz, General Rodríguez, Grand Bourg) y Capital Federal (Calzato, 2005c). En la provincia de Corrientes posee dos formas iconográficas: la más común es una figura esquelética que porta una guadaña, y puede ser de yeso, madera o metal. En este caso se le denomina, entre otras formas, como Señor de la Buena Muerte, San Esqueleto, etcétera (figura 1). La segunda versión es una pequeña figura, por lo general construida en madera, con un rey con su corona sentado, y a la cual se denomina San Justo, San Bernardo o San Paciencia (figura 2). El material utilizado para la confección de imágenes en algunos casos es hueso. Actualmente se ven en santerías imágenes de considerable tamaño realizadas con yeso. En la provincia de Buenos Aires y Capital Federal prevalece la imagen esquelética con guadaña. Cada santuario se encuentra a cargo de una "Cuidadora y dueña del santo", que cumple un rol social muy importante entre los allegados al culto y que en la mayor parte de los casos ejerce funciones de sanación espiritual y videncia. 
Por lo general, las fiestas del santo se realizan entre los días 15 y 20 de agosto de cada año. Cada santuario posee su modalidad de festejo, pero normalmente se conmemora el cumpleaños del santo con asado, baile, procesión y rezo del Rosario.

La forma devocional básica consiste en pedidos de salud, amor y trabajo. Otra forma devocional es utilizar al santo para hacer daños como procurar accidentes, divorcios, enfermedades o muertes. No parece, hasta lo visto, que éstas prácticas se den en la provincia de Buenos Aires. La información proviene de diversos informantes en la provincia de Corrientes.

Una de las formas extremas de devoción consiste en introducir en la piel (abdomen, brazos o piernas) un San La Muerte muy pequeño, hecho de hueso humano (específicamente de "cristiano bautizado"), con el fin de procurar una "buena muerte"; es decir para que el santo proteja al devoto de una muerte violenta como víctima de balas o cuchillos. Esta práctica la llevan a cabo individuos privados de libertad, como reclusos, o aquellos en libertad vinculados con actividades delictivas. Se posee información de esta práctica en Corrientes, mientras que en Buenos Aires se utilizan tatuajes para el mismo fin. De una u otra manera, este tipo de devoción se acerca a lo visceral, pues se trata de introducir en el propio cuerpo la deidad que se venera. Este pacto genera una relación más con el santo que se establece tomando como mediación el propio cuerpo, donde el nexo entre ambos (cuerpo/San La muerte) se establece de por vida.

A diferencia de la umbanda y quimbanda, donde las entidades pueden "incorporarse", como es el caso de Tranca Rúa o el Tata Cabeiras, representantes de la muerte en el pensamiento afro-católico-brasilero, San La Muerte no se incorpora a sus devotos. ${ }^{2}$ Algunos creyentes mencionan a San La Muerte como dueño de las almas del cementerio, pero nunca en incorporación. La propia liturgia ritual atestigua el lugar que ocupa el santo: rezo y bailes. En los encuentros comunitarios desaparece todo accionar esotérico. Las dueñas del santo (aquellas personas que cuidan y se encargan de los santuarios durante todo el año) se autodenominan clarividentes o "médiums" (en un sentido limitado de la definición de Kardec, dado que se refieren al poder de curar y no estrictamente de posesión) e intercesoras entre los devotos, los clientes ocasionales y el santo.

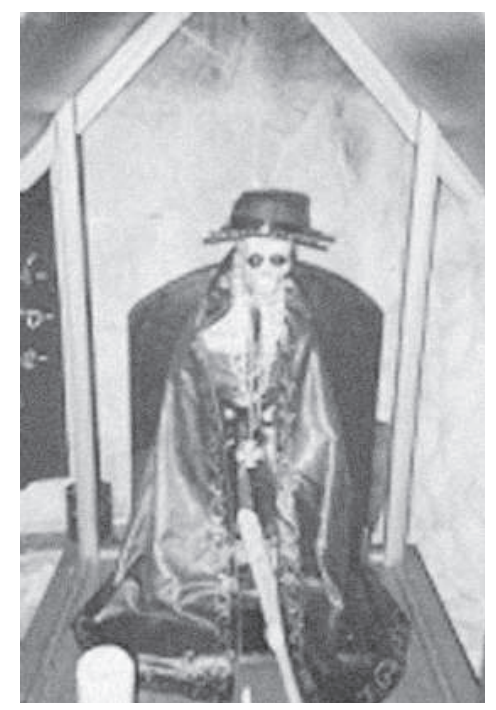

Figura 1: Santuario del Hermano, Claypole, provincia de Buenos Aires.

De carácter católico por su estructura devocional (rezo del Rosario, alusión a Jesucristo, vinculación con la presencia continua de alguna veneración mariana), San La Muerte se caracteriza por su profunda a-historicidad (no fue un santo que depositó sus pies en esta tierra, no posee una historia humana de referencia) y su a-escatología (pese a la presencia de la muerte, lo devotos no hacen alusión a la vida en el más allá, como una consecuencia de entablar una relación con la muerte). Esto lleva a los devotos a construir alrededor del santo toda una interpretación acerca de la vida y su significado.

En escritos previos me referí a la situación marginal, social y económica de los devotos de la provincia de Buenos Aires (Calzato, 2006d). Esta investigación comenzó en enero de 2002 en la provincia de Corrientes y se pro- 
longó hasta 2007 (últimas entrevistas) en la provincia de Buenos Aires. Son los años clave de la economía en desastre, luego de la crisis y del abandono del poder del ex presidente Fernando de la Rúa. Pude comprobar, a través del trabajo de campo, la profunda depresión del conurbado bonaerense. San La Muerte tuvo, y tiene desde esa fecha, una considerable cantidad de devotos en aumento que piden y solicitan una explicación a tanta desventura.

\section{Como una experiencia próxima (carácter devocional)}

En trabajos anteriores hablamos sobre la necesidad de ubicar el culto a San La Muerte dentro de un par dicotómico. ${ }^{3}$ Entendemos que toda experiencia religiosa se concentra en una dualidad cerca/lejos. Lo lejos, en este caso, serían las instituciones que pretenden representarnos; se incluyen religiones oficiales donde la santidad cobra un sentido lejano, donde las liturgia y la ética se interponen entre el devoto y el santo. Lo cerca es aquella experiencia religiosa donde el devoto entabla con el santo una relación de proximidad. Es "su santo", con el cual se enoja, puede castigarlo, lo convierte en su protector personal: se ubica dentro una esfera de experiencia próxima (Calzato y Cirio, 2003). San La Muerte, lejos de ser la parca que nos viene a buscar (clásica figura medieval) es el santo amigo y protector. No es un fin, sino un principio. Es el amigo que cuida a la familia; "El negro" o "El Flaco", ése que cuida a los devotos mientras transitan una noche oscura a la vuelta del trabajo. Es el que acaricia a sus fieles cuando le rezan. Es el santo de la proximidad. Todo se concentra en él. Hasta el momento de la muerte, el santo resguarda, cuida y protege, y se comunica por medio de sueños y avisos. Por lo general, las condiciones de marginalidad social y económica en la cual se desarrolla el culto a San La Muerte permiten ahondar esa relación de los devotos con respecto a su santo, debido al abandono de las instituciones oficiales.
El acercamiento de los devotos inicia, por lo general, luego de una experiencia límite, como una enfermedad, soledad o una situación que requiera una poderosa ayuda para su solución. Usualmente esta experiencia se da en todo terreno religioso. Pero en el caso de San La Muerte la práctica devocional, desde un principio y durante el proceso de la misma, se transforma de modo profundo y se convierte en una intima relación con el santo. En las devociones marianas podemos ejemplificar esta relación con el término de "horizontalidad". Aunque la experiencia mariana no deja de ser profunda, entiendo que no ofrece cambios por parte del devoto. Incluso muchas veces los marcos de la devoción se estructuran institucionalmente, cuando la devoción mariana pasa a representar una situación patriótica determinada, como en México, Argentina o Nicaragua.

Pero, ¿Qué ocurre con los devotos respecto a San La Muerte? La intimidad adquiere dimensiones profundamente diferentes. El pathos de la mayor parte de los devotos transita, nada más ni nada menos, que en la relación con la muerte y la violencia.

En una entrevista, dos devotas de la localidad de Villa Domínico, provincia de Buenos Aires, lo explicaron de la siguiente manera:

Graciela (G): Eso sería bueno que lo vea, a mi marido lo asaltaron y le sacaron la moto y le gatillaron dos veces y el tiro no salió, siempre lo llevaba en el bolsillo, y hacía una semana que yo le venía diciendo que algo le iba a pasar de noche, no me hace caso, que es la verdad, después empezó una semana antes que empezó a ponerse el santo en el pecho para colgárselo, porque yo lo hago en una bolsita roja.

Antropólogo (A): ¿De qué material lo hace?

G: Plomo de bala y plomo común.

A: Porque en Corriente se hace en hueso...

G: Yo le dije que si era para hacerlo... yo tenía, a mí me habían traído para hacerlo si era que había que hacerlo, bueno que llegue acá [...] sino no que se vaya [...] como ven no lo sigo haciendo así, mi marido lo 
tenía colgado acá cuando le gatillaron y no le salió el tiro, dos tiros.

A: O sea que te protege de la muerte, la muerte violenta

G. Sí, Sí.

A: Que no quiere decir que te proteja de la muerte natural.

G: iClaro!

A: Me gustaría que me comente sus puntos de vista sobre eso.

G: Claro. Más bien que sí es así.

Susana (s): O sea, cuando es la muerte natural, es inevitable eso, ¿no? Pienso que así como todos nacemos, tenemos que morir; es la naturaleza, la ley de la vida, pero sí que te protege de todo lo malo que puede haber a tu alrededor, todo lo malo, todo, todo, todo. No sé cómo decirte, que yo me iba a trabajar y venía once y media de la noche, me venía caminando desde allá y en esa hora te encontrás todo en la calle, jamás me ha pasado nada; otra cosa, mientras estaba trabajando, cada vez que iba a haber problemas era fija porque una cosa que, me acariciaban la espalda acá, en la espalda y en el roce de la pierna, siempre fue así y era fija cada vez que pasaba algo malo, pero siempre me cuidaba cosa de que yo no hacer nada perfecto, todo bien era un aviso que iba a pasar y pasaba, porque pasaba, pero siempre quedaba bien parada yo, porque yo sabía que algo malo iba a pasar [...] como, cómo te lo puedo explicar esto, no sé.

(...)

G: Le explico. Que yo tenga San La Muerte, para morir tranquila me tienen que enterrar el santo, porque dicen que cuando uno lo tiene no puede morir, se puede morir uno, tanto que se aferra a la vida, está sufriendo, pero no se puede morir, la abuela de mi hijo más grande, ella lo tenía el San La Muerte en Corrientes, y antes de fallecer lo dijeron que enterrara al santo porque si no ni podía morir.

A: iAh! enterrar el santo.
G: Sí, hay que enterrarlo; entonces, después la persona muera tranquila, descansa, pero primero hay que enterrarlo a él (Graciela y Susana, provincia de Buenos Aires, 15 de agosto de 2004).

Cuando hablamos de devociones marianas nos referimos, retornando un poco a la definición de experiencia religiosa de Kasper, a unas coordenadas históricas que legitiman la conducta y los discursos. Hablar de la Virgen María es hablar de una experiencia religiosa del pasado que se encuentra en una legitimidad histórica profunda que nos antecede. Cuando contemplamos una imagen de la Virgen de la Medalla Milagrosa obran, en nuestro cerebro, cientos de imágenes y conceptos que nos ayudan a entender, si es que cabe la palabra, qué es lo que tenemos enfrente, y no solamente por la imagen y los relatos, sino porque una institución como la Iglesia Católica guarda en su seno, a modo de matriz, una significación de dicha imagen.

San La Muerte no tiene una historia que lo legitime histórica e institucionalmente. Ninguna institución lo guarda en su seno. Por eso muchos devotos lo ubican a la diestra de Dios, como el poder de la muerte, sin más; incluso, en algunos casos, a la orden del mismo Jesucristo. Una oración para el santo lo denomina como "Señor de la historia y del tiempo".

\section{Castigo y violencia}

En un segundo caso analicé el concepto de castigo y violencia que se atribuye al santo en su círculo devocional (Calzato, 2004a). La relación con los devotos conlleva, además de la protección, el cuidado que los fieles deben tener; devoto que no cumple con sus promesas es castigado por el santo de una manera muy severa: puede quitarle un familiar, alguna propiedad o enviarle una enfermedad. "Al santo se le cumple" (Graciela, Villa Domínico, provincia de Buenos Aires). El santo posee los dos polos, la protección y el castigo. Esta dicotomía 
en la religiosidad popular fue tratada por Michel Maffesoli (2005); este autor analiza cómo el pensamiento alternativo, y específicamente el religioso popular, conlleva siempre el bien y el mal como depositarios de una realidad profunda. Mientras que en el pensamiento Aristotélico-tomista prevalece el principio de no contradicción, nada puede existir diferente a sí mismo, los santos alternativos, los que no pertenecen a una esfera de legitimidad, cargan en sí tanto el bien como el mal. Esto el autor lo atribuye, en este caso, a la pesada carga institucional eclesiástica que se heredó de la conquista española en América. Constante antropológica que se encuentra de la misma manera en el pensamiento poético. Nada sería tan irreal, manifiesta el autor, sin el equilibrio entre la bondad y la maldad.

\section{El más allá}

Por último hay que ver los conceptos de escatología clásica y la reconstrucción, por parte de los devotos del concepto de muerte y el más allá (Calzato, 2004b). Comentaba, en este último trabajo, que el concepto de la muerte difiere de las definiciones clásicas escatológicas. ${ }^{4}$ Estas nociones están ausentes, no les preocupa el más allá, sino el más acá, la solución a sus vidas y problemas. Por eso hablé de a-escatologización, que los devotos de dicho santo manifiestan continuamente a través de sus discursos y práctica devocional cotidiana.

Lucrecia es dueña del santo del Templo de General Rodríguez, provincia de Buenos Aires. Capacitada en magia negra y ocultismo en Brasil, ejerce su liderazgo como una de las cuidadoras del santo más reconocidas en el territorio argentino:

Antropólogo (A): Muchos devotos, después de escucharlos durante tantos años, no me hablan del más allá.

Lucrecia (L): Yo estuve en el más allá. Yo en una oportunidad, de esto te digo hace diez años, yo le dije a él, no sé qué había pasado que yo le pedí a él, me acuerdo que abrí la puerta y el dije: santito: ¿Vos estás conmigo o no estás conmigo? Esas fueron mis palabras.

Viene mi sobrina en moto y me dice: -Tía, ¿Vamos a comprar un paste a la ruta?

Si, bueno, - - le dije, pero no vamos por acá, vamos a pegar la vuelta, le contesté.

En eso venía, había llovido y venía un tractor de frente, entonces, venía manejando un nene de 14 años, porque el padre venía ebrio atrás de él, enseñándole a manejar. Entonces yo le dije a mi sobrina, pará la moto.

- ¿Por qué? - me pregunta mi sobrina.

-Pará la moto --le contesté-, porque éste nos va a atropellar.

-No, tía.

-Nos va a atropellar, Laura - le dije.

-No tía, no puede ser.

-No terminó de decir ella... que se nos tira el tractor encima y el golpe a mí me mandó abajo del tractor, yo iba atrás. A mí me mandó, yo pasé por encima de mi sobrina y caí abajo del tractor. Me arrastró cincuenta metros. A ella la moto le quedó enganchada acá y la rueda y el tractor, la rueda del tractor le pasó por encima a mi sobrina, aplastándola la moto. Yo lo único que dije, yo llevaba una medalla de San La Muerte, y dije: "Santito, yo no quiero morir así". Yo estaba toda ensangrentada. La rueda del tractor me pellizcó todo este lado, todo [me señala parte de su cuerpo]. Esta mano me la hundió, me la hundió, mientras tanto me iba arrastrando. Cuando yo salí debajo del tractor, hice unos metros y caí. De ahí no me acuerdo más. Yo lo único que te digo, yo estuve muerta. Yo estuve allá arriba y estaba él al lado mío [el santo]. Y yo miraba a mis hijos que me abrazaban. La vi a mi mamá que me tenía agarrada del [...]. Lo vi a mi hijo mayor que me decía: "No te mueras mamá. No te mueras. Por favor". A: Vos los veías como desde...

L: De muy alto. Yo estuve muerta.

A: ¿Y con quién estuviste allá?

L: Con él. [Me señala la imagen de San La Muerte, 
que se encontraba en su santuario, donde se realizó la entrevista]. Estuve con él, estuve con mi nieta, con mi papá, con el hermano, con mi sobrino. Yo creo que estuve muerta veinte minutos. Yo los miro a ellos y miré a mi nieta, que me estiraba la mano. Yo le dije: "no Deniz", yo no puedo darte la mano ahora; yo tengo tus hermanitos iMe entendés? Yo tengo tus hermanitos y los tengo que criar". Alguien me toca el hombro, me doy vuelta y mi padre me dijo: - "Andá que te necesitan" —-me dijo-. Entonces, para mí yo iba caminando, como te... entre nieve. Era todo blanco. Miro así y San La Muerte me pegó un empujón, un golpe en la espalda. Que hasta hoy lo siento.

A: ¿Cómo lo viste a San La Muerte?

L: Así [me señala una gran imagen del santo que se encontraba en el santuario]. Grande así con esa capa. Él me pegó un golpe en la espalda, que hasta hoy siento ese golpe, cuando se ve que yo bajo, vuelvo y pego un grito, ya estaba llena de sangre, nariz, boca, no me quebré, el tractor me pasó por encima, yo no tuve una quebradura.

A: ¿Su sobrina?

L: Tuvo trombosis en las piernas. Coágulos de sangre. Yo también tuve coágulos de sangre. En brazos, pechos, todo. Yo creo que él me dio otra oportunidad. Entonces me demostró que él está conmigo. Él me lo demostró. Y nunca más dije eso. Nunca más. Nunca más. Yo sé quién es él. Me dio una oportunidad. Yo tenía que hacer mucho por las criaturas, por un montón de cosas. Porque no es mi hora todavía.

Pese a haberse encontrado en el más allá, la resolución del discurso de Lucrecia se traduce en la necesidad de llevar a cabo su trabajo en este mundo, en este suelo.

Con respecto a la vida en el más allá, Nilda, asidua devota del templo de Claypole, en la provincia de Buenos Aires, considera que ésta es la vida que nos toca vivir. Si hay otra existencia ultraterrena, es la del alma y la del espíritu, pero la vida es ésta, después no hay otra:
Para mí, el mundo es éste; después, lo que flota en el aire es el alma y el espíritu [...] Pienso que el alma se va al cielo, lo demás ya queda acá, lo demás ya se termina. Hay una sola vida. Habrá dos mundos, para el alma. Yo soy católica, pero hay un solo mundo; los que se van, no vuelve ninguno. El mundo que vivimos es éste (Leonilda, febrero 2004).

\section{Discusión}

\section{I}

A modo de hipótesis: cuando la cohesión social se quiebra, el futuro y sus promesas se desvanecen; cuando el abandono existencial y social se cierne urge la necesidad de encontrar una salida en el aquí. Se instala en nuestra conciencia que en ese momento no podemos cruzar el mar, por más que lo deseemos. Nos urge encontrar una salida. Pero ésta no es unívoca. No todas las experiencias religiosas discurren sobre el mismo camino. El pueblo de Israel comenzó con las ideas de inmortalidad del alma luego de su exilio en Babilonia, en plena crisis, cuando todas sus creencias se desvanecieron fuera de su tierra. Por el contrario los creyentes del santo elaboran su propia creencia sobre un accionar basado en el acá, en la vida de todos los días. El quiebre de la cohesión social, en este caso, no permitiría concentrarse en las retribuciones en el más allá. No se encontraría un escape hacia el paraíso como compensación.

\section{II}

Todo el acontecer del hombre posee su término, su límite, su finitud. Esta situación de angustia se resuelve de muchas maneras, nunca de manera unívoca. La muerte y el final acosan a cada hombre. Pero la actitud que tomemos frente a esta desesperación no es arbitraria; una profunda estratigrafía es el peso que lleva a hombres y sociedades a tomar una actitud específica con lo que nos acontece. Nuestras actitudes son el resultado de una situación biográfica particular. 
Los devotos del santo que nos ocupa reconstruyen de manera cotidiana su relación, en este caso personificando ${ }^{6}$ a la muerte, alejando la idea de un más allá a la propia muerte. Nos encontramos bajo dos parámetros. Un culto que venera a la muerte, pero al mismo tiempo le arranca su ropaje escatológico. Su acción se concentra en este mundo, en "este aquí" que nos toca en el reparto. Por otro lado, pese a todo, pese a la situación de crisis profunda, existencial y social de angustia primera, los devotos no piensan en un más allá como recompensa a esta vida. La ensoñación del paraíso, frente a los infiernos cotidianos, es una de las más fuertes tentaciones. Pero a los devotos de San La Muerte parece no importarles. Debemos tomar en cuenta que la noción de "suelo", definida por Kusch, es necesario ubicarla en su propia urdimbre: las condiciones sociales de ese "suelo", su historia, sus modos de supervivencia y su accionar económico.

El "suelo" no nos viene solo, sino con el peso de nuestras lecturas y reinterpretaciones, con lo que nos enseñaron de él. La historicidad de Kasper nos puede ayudar a entender la intersección entre un "suelo", su pasado, su presente y la experiencia próxima donde leemos de qué se trata. En esta urdimbre nos movemos.

\section{III}

La religiosidad popular se caracteriza por una fuerte motu propio con respecto a las instituciones oficiales (Marzal, 2002). Posee su propia creatividad y anda sola por el mundo. Establece sus propios tiempos, su propia liturgia y su propio accionar. Le debe mucho a esas instituciones, pero sabe caminar sola (González, 2002).

Los devotos de San La Muerte han sabido construir su propio camino frente a los oscuros arbitrios institucionales. Su énfasis es este mundo del sentido común de la vida cotidiana, ${ }^{7}$ donde se transita y donde se busca el hilo de Ariadna de nuestras vicisitudes. ${ }^{8}$ El dolor de la marginación se resuelve en este mundo. En este caso dolor y futuro no son compatibles. Creo que aquí es el único lugar donde el principio de contradicción cum- ple su papel en terreno popular. De una u otra manera Lucrecia sabe que su accionar debe desenvolverse en este mundo. El más allá ejerció su fascinación, pero lo encomendado debe resolverse aquí.

Podemos agregar que la a-historicidad del santo, en el sentido de no haber transitado los caminos de la hagiografía tradicional, invita a sus devotos a concentrarse en el dominio de este mundo. El antes y después sólo son adverbios de tiempo. Si mi pasado se encuentra quebrado, si mi presente se rompe a cada instante, el futuro no puede ser distinto. La secularización propia de la religiosidad popular americana y el "desencanto" del mundo, desde la revolución industrial, hacen su propio agosto. Esa ilegitimidad que no posee pasado ahonda el presente. Ahonda este ser ahí, este ser en el mundo. Por lo pronto, entonces, este mundo es lo único que nos queda, este suelo, esta materialidad. Aquí lo sagrado toma carácter de trama, donde los tejidos de la existencia se entrecruzan, donde el poder de la muerte y su presencia se dignan a hacerles compañía y a no dejarlos solos. Este ser aquí se traduce en el grito íntimo de la existencia. A diferencia del grito de Munch, que se adhiere a su plasticidad y es sólo superficie, el grito de los hombres posee volumen y se desarrolla en un espacio.

\section{Conclusión}

Existe una finitud de la cual ninguno de nosotros puede escapar. Este límite, este sentirnos arrojados nos lleva a preguntarnos sobre el sentido de nuestra existencia. La experiencia religiosa, la preocupación última, al mismo tiempo que ahonda este misterio nos procura algunas explicaciones. Pero este caminar con la preocupación última se desarrolla en un "suelo", con características socio culturales particulares. Este "suelo" que ya se encuentra construido cuando venimos al mundo y seguirá existiendo cuando nos vayamos condiciona nuestros pasos y nos brinda atisbos para encontrar el hilo que pueda desenvolver la madeja. Por eso las experiencias religiosas no son unívocas. Se suma el "suelo" cultural y 
San La Muerte (Argentina). Devoción y existencia.

nuestras propias experiencias, nuestra biografía. Ambas se funden en el caminar.

De manera particular los devotos de San La Muerte, quienes desarrollan su acción en la provincia de Buenos Aires, asumen su experiencia religiosa aferrados a este mundo que se encuentra bajo nuestros pies, nuestro "suelo" que se asienta a su vez en una suerte de finitud que nos condiciona. Asumen esta finitud, no le escapan. Pese a todo, esta "superficie" es la que les brinda la gravidez necesaria, de su equilibrio. Las tramas y sus relaciones con el "otro" se fundamentan a través de este "suelo", tal como fue definido. Los devotos centran su atención en el mundo del más acá. El quiebre de su cohesión social, que acompaña a la marginalidad económica-social, los lleva a desdeñar un paraíso lejano. Tratan de solucionar sus avatares en el marco de su vida cotidiana, donde prima el sentido común como terreno de su experiencia. Este ahondamiento del presente, esta necesidad de encontrar una solución a los avatares de la vida, este quiebre existencial que los devotos asumen enteramente hace que el más allá sea uno de esos paraísos perdidos y pierda su interés. Los devotos enfrentan esta situación construyendo una profunda relación con su santo, una relación "cercana”. Se suple el abandono existencial con un santo que no posee historia, que no nos lleva a los cielos, que nos abandona en el momento de la muerte, pero que posee la fuerza suficiente para solucionar gran parte de los avatares que encontramos en este "suelo". El punto en cuestión es el entrecruce entre una deidad ahistórica, a la que se niega su escatología, centrada en un presente, y el propio pasado del devoto, su síntesis biográfica, su vida, sus dolores y su pesar. Es en esta intersección donde se desenvuelve la praxis devocional.

Las experiencias religiosas son el producto de una objetividad precisa, hechos que nos ocurren, cosas, momentos, incertidumbres que se quedan prendidas, en lenguaje bíblico, a nuestros riñones (como la parte más profunda de nuestra personalidad) y por ello nos sentimos arrojados en este mundo, en caída, que se instala con un pasado y un presente, que se construye cotidianamente. La "preocupación última" no existe sola, no viene en nubes, coexiste con nuestros avatares de todos los días, el mundo que transitamos y al que, a través de nuestras acciones y preguntas, tratamos de encontrar un sentido. Cada uno a su manera: el devoto con su santo, y el antropólogo con sus escritos.

\section{Notas}

${ }^{1}$ El problema se suscita cuando intentamos definir qué significa "conversión”. Hasta la década de 1980 se consideraba la conversión, según el modelo de la experiencia paulina, como un cambio muy súbito del individuo, dramático, que transformaba totalmente su forma de vida. Estas concepciones datan de las décadas sesenta y setenta. Estos puntos de vista partían de una concepción del individuo basada en la pasividad, con ciertas características psicológicas o sociales que lo inclinaban a pertenecer a determinados movimientos religiosos. A partir de 1980 esta concepción cambia y se trata a la conversión como un proceso de cambio desde lo interaccional y procesual (Frigerio, 1993). No existe una definición unívoca de conversión. Manuel Marzal la define como un "complejo proceso por el cual cierta persona abandona la religión en que se ha socializado y ha practicado con más o menos fidelidad, para abrazar otra" (2002: 509). Este autor estudia la conversión de los católicos al evangelismo, analizando los pormenores propios de estos últimos: tipos de contacto, proselitismo, experiencia de sanidad, contacto con la Biblia, etcétera. que la convierten en un fruto deseable para algunos católicos. Desde el punto de vista teológico la experiencia del apóstol Pablo ya no se considera una conversión. Según Rivas (2001), es preferible hablar de vocación, dado que Pablo no renegó de su condición judía; consideró (¿o considero?) su accionar como una perfección o comprensión correcta del judaísmo al cristianismo. Por su lado Fitzmyer (1975) prefiere hablar de una "revelación" y no de conversión debido a que primero esta revelación 
dejó plasmada en Pablo "la unidad de acción de Dios" (1981: 62), segundo, "le enseñó el valor soteriológico de la muerte y resurrección del Jesús Mesías (1981: 63) y tercero, "aquella visión dejó grabada en Pablo una nueva concepción de la historia de la salvación” (1981: 64).

2 El concepto de mediunidad es definido por Alan Kardec, fundador de la teoría espiritista, de la siguiente manera: Toda persona que siente en cualquier grado la influencia de los espíritus, es por esto mismo médium. Esta facultad es inherente al hombre y por consecuencia no es un privilegio exclusivo; así es que hay pocos entre los que no se encuentran algunos rudimentos. Se puede pues decir que casi todos somos médiums. Sin embargo, en el uso, esta calificación sólo se aplica a aquellos cuya facultad medianímica está claramente caracterizada y se conoce por los efectos patentes de cierta intensidad, los que dependen de una organización más o menos sensitiva. También debemos notar que esta facultad no se revela en todos de la misma manera; los médiums tienen generalmente una actitud especial para tal o cual orden de fenómenos y esto consiste que se hagan tantas variedades como hay clases de manifestaciones. Los principales son: los médiums de efectos físicos, los médiums sensitivos o impresionables, auditivos, parlantes, videntes, sonámbulos, curanderos, neumatógrafos y escribientes o psicógrafos" (1969: 123). De esta manera los médiums pueden "incorporar" en sus cuerpos espíritus o entidades. Es decir la entidad toma posesión del cuerpo. No debe confundirse con la posesión exorcista. Ésta ocurre cuando la persona, sin ser médium, es tomada por un espíritu de manera violenta, sin consentimiento propio. Cuando hablo de "incorporación" me refiero al contacto y a la búsqueda ex profeso de un médium o pai (sacerdote afro). En este sentido, la liturgia de San La muerte no incluye rituales o pedidos de posesión.

3 "El par dicotómico propuesto para la comprensión de la dinámica y la vitalidad de este culto, lejos-cerca, es una construcción mediada por la intersubjetividad del conjunto de los devotos del santo. Lo lejos es lo institucional, pues no obtienen respuesta a sus demandas ma- teriales e inquietudes sobre lo absoluto, o por lo menos no en la medida de sentirse satisfechos. Lo cerca, por el contrario, son los santos, sus amigos, sus compañeros de morada, los seres sobrenaturales protectores siempre, en los que los devotos pueden confiar plenamente y efectuarles pedidos, con la certeza que la fe en ellos impone para lograr la solución de sus problemas. Así, en el cotidiano peligro que ocasiona la marginación social y económica, en el caso de los devotos provenientes de los sectores subalternos, la muerte se convierte en una entrañable compañera que garantiza un buen decurso de vida para llegar a una buena muerte, a una muerte cristiana, no violenta. Como vimos, también integran el culto personas de niveles económicos medios y medios altos. En estos casos, el poder de atracción que tiene la Parca sobre ellos parece venir de la talla de sus profesiones: médicos y abogados en su mayoría, profesiones en la que el contacto y el comercio con la muerte y la violencia son frecuentes" (Calzato y Cirio, 2003: 339).

${ }^{4}$ La Escatología (del griego escathon o eschata) se refiere a las últimas realidades del hombre, las que concierne a la vida en el más allá o al destino de la humanidad. También involucra el destino individual más allá de la muerte.

${ }^{5}$ Nieta fallecida unos años atrás.

"Entiendo por "personificación" el hecho de que a la muerte los devotos le confieren una personalidad determinada. Para la teología católica la muerte es un estado, en cambio para los creyentes es un amigo, su protector, quien ayuda o castiga.

7 "El sentido común, por su parte, no tiene inclinaciones teóricas. Se ciñe completamente al mundo familiar de las cosas relacionadas con nosotros. Las preguntas ulteriores están confinadas por los intereses y preocupaciones de la vida humana, por el éxito en la ejecución de las tareas cotidianas, por el descubrimiento de soluciones inmediatas que resulten eficaces. En verdad, la norma suprema del sentido común es la restricción de las preguntas ulteriores al ámbito de lo concreto y particular, de lo inmediato y lo práctico. Desarrollar el sentido común implica contener el impulso omnívoro de la inte- 
ligencia inquisitiva y desdeñar por impertinente, si no tonta, cualquier pregunta cuya respuesta no produzca una diferencia inmediatamente tangible (...) Al fin y al cabo, la gente con sentido común está muy ocupada: tiene por delante todo el quehacer del mundo (Lonergan, 1999: 250).

8 "Con respecto a otros ámbitos de realidad con una estructura de sentido finita, el mundo de la vida cotidiana es la realidad primaria. Ya hemos examinado minuciosamente por qué: el mundo de la vida es el ámbito de mis actos corpóreos vivos: ofrece oposición y exige un esfuerzo para superarla. La realidad cotidiana me plantea tareas y debo realizar mis planes dentro de ella. Me permite triunfar o quedarme frustrado en mis intentos de concretar mis objetivos. Mediante mis efectuaciones me inserto en la realidad cotidiana y la modifico. Puedo verificar los resultados de mis actos como sucesos dentro de un mundo intersubjetivo y por ende "objetivo". Puedo dejar que los verifiquen otros, separados del proceso subjetivo generador, independientes de las circunstancias, de modo que la realidad cotidiana pueda ser producida mediante mis actos. Comparto mi realidad con otros hombres, con quienes tengo en común no sólo objetivos, sino también medios para la concepción, para la concreción de estos iobjetivos? Influyo en otros hombres y estos en mí. Podemos actuar juntos. El mundo de la vida cotidiana es aquella realidad en la cual es posible la comprensión recíproca" (Kusch, 1991: 63).

\section{Bibliografía}

Calzato, Walter y Pablo Cirio, 2003, "Lo lejos y lo cerca", en Actas de III Jornadas de Patrimonio Intangible: "El espacio cultural de los mitos, ritos, leyendas, celebraciones y devociones", Centro Cultural General San Martín, Buenos Aires, Secretaría de Cultura de la Nación, agosto, pp. 330-342.

Calzato, Walter, 2004a, "Escatología y dimensión social (San La Muerte, Argentina)", en Diálogo Antropológico, revista digital del Posgrado en Antropología de la Fa- cultad de Filosofía y Letras, Instituto de Investigaciones Antropológicas, Universidad Nacional Autónoma de México, núm. 9, noviembre, pp. 13-22.

—, 2004b, "Tú no tienes marías que se van. El caso San La Muerte (Argentina)", en Actas de las siete Jornadas Rosarinas de Antropología Sociocultural, 21 y 22 de octubre, versión en disco compacto, Universidad Nacional de Rosario, Facultad de Humanidades, Argentina.

—, 2005c, "San La Muerte. Praxis y formas devocionales (Provincia de Buenos Aires, Argentina)", en Primer Congreso Latinoamericano de Antropología, 11 al 15 de julio, disco compacto, Rosario, Argentina.

—, 2006d, "Después de todo, ¿Quién se come a los monstruos? (San La Muerte, Argentina)”, en revista Coexistencia, Escuela Nacional de Antropología e Historia, núm. 4, pp. 33-45.

Chapp, María Ester, 1991, "La recuperación de la experiencia religiosa en el pensamiento sociopolítico", en Chapp, M. E., Iglesias M. et al (coordinadores), Religiosidad popular en Argentina, Centro editor de América Latina, Buenos Aires, pp. 24-44.

Fitzmeyer, Joseph A, 1975, Teología de San Pablo, Ediciones Cristiandad, Madrid.

Frigerio, Alejandro, 1993, "Perspectivas actuales sobre conversión, deconversión y 〈lavado de cerebros”, en Frigerio, A, Carozzi M. J. Mónica Tarducci (coordinadores), Nuevos movimientos religiosos y ciencias sociales I, Centro Editor de América Latina, Buenos Aires, pp. 46-80.

González, Gazques, Gustavo, 1989, "Cultura” y "Sujeto cultural", en El pensamiento de Rodolfo Kusch, Kusch y el pensar desde América, Azcuy, Eduardo (compilador), Fundación García Cambeiro, Buenos Aires.

González Martínez, José Luis, 2002, Fuerza y sentido. El catolicismo popular al comienzo del siglo XXI, Ediciones Dabar, México.

Kardec, Alan, 1969, El libro de los médiums, Kier, Buenos Aires.

Kasper, Walter, 1982, El Dios de Jesucristo, Sígueme, Salamanca

Kusch, Rodolfo, 1991, Esbozos de una antropología filosófica americana, Castañeda, Buenos Aires. 
—, 1975, La Negación en el pensamiento popular, Cimarrón, Buenos Aires.

—, 1976, Geocultura del hombre americano, Fernando Cambeiro, Editor, Buenos Aires.

—, 1986, América profunda, Bonum, Buenos Aires.

Lonergan Bernard, 1999, Estudios sobre la comprensión humana, Sígueme, Salamanca.

Maffesoli, Michel, 2005, La Tajada del diablo. Compendio de subversión posmoderna. Siglo XXI Editores, Buenos Aires.
Marzal, Manuel M., 2002, Tierra encantada. Tratado de antropología religiosa de América Latina, Trotta, Universidad Pontificia de Perú.

Rivas, Luis Antonio, 2001, San Pablo. Su vida, sus cartas, su Teología, San Benito, Buenos Aires.

Steiner, George, 1999, Heidegger, Fondo de Cultura Económica, México.

Tillich, Paul, 1972, Teología sistemática, la razón y la revelación. El ser de Dios, vol.l, Libros del Nopal, Barcelona. 